\title{
The acrocentric part of $\operatorname{der}(\mathrm{Y}) \mathrm{t}(\mathrm{Y} ; \mathrm{acro})(\mathrm{q} 12 ; \mathrm{p} 1$ ?2) contains D15Z1 sequences in the majority of cases
}

\author{
Sigrid Fuchs ${ }^{1}$, Jasmin Lisfeld ${ }^{1}$, Stefanie Kankel ${ }^{2}$, Luisa Person ${ }^{2}$ and Thomas Liehr (iD ${ }^{2 凶}$
}

(c) The Author(s) 2021

Chromosomal heteromorphisms (CHMs) are currently largely disregarded in human genetic diagnostics. One exception is der( $\mathrm{Y}) \mathrm{t}(\mathrm{Y}$; acro)(q12;p1?2), which has at least been mentioned in karyotypes and discussed in reports. This derivative is frequently observed in healthy males with idiopathic infertility, which is not uncommon for CHMs. Here, we present the first systematic fluorescence in situ hybridization (FISH)-based study of 7 carriers of $\operatorname{der}(\mathrm{Y}) t(\mathrm{Y} ; \mathrm{acro})(q 12 ; p 1$ ?2). Specific probes for 15p11.2 (D15Z1) and 22p11.2 (D22Z4) were applied to answer the question of whether either of the short arms may be involved in the formation of the derivative Y-chromosome. In 6 out of 7 cases, specific staining was achieved using the D15Z1 probe, while the derivative acrocentric chromosomal region was not positive for D22Z4 in any of the 7 cases.

In conclusion, this study implies that the acrocentric chromosomal region is derived from chromosome 15 in the majority of cases with $\operatorname{der}(\mathrm{Y}) \mathrm{t}(\mathrm{Y} ; \mathrm{acro})(\mathrm{q} 12 ; \mathrm{p} 1$ ?2).

Human Genome Variation (2021) 8:1-3; https://doi.org/10.1038/s41439-021-00163-9

\section{INTRODUCTION}

In routine human banding cytogenetics, specific chromosomal regions are prone to showing variation. In addition to the pericentric regions of chromosomes 1,9, and 16, the long arm of the Y-chromosome and, especially, the short arms of all acrocentric chromosomes are most frequently affected by changes in size and structure. These changes that are not associated with adverse clinical outcomes and are passed down through many generations are called chromosomal heteromorphisms $(\mathrm{CHMs})^{1,2}$. The new formation of $\mathrm{CHMs}$ has rarely been identified ${ }^{3,4}$.

In a study conducted in the general population, shortened acrocentric short arms were found in 34/30,117 individuals (0.11\%) and enlarged acrocentric short arms were found in 149/39,773 individuals $(2.38 \%)^{1}$. As all five human acrocentric chromosomes (i.e., 13, 14, 15, 21, and 22) have short arms that contain (if at all) only a few genes, size variations in these regions have no measurable influence on the carrier's phenotype. The only known genetic contribution of the short arms is that all of them typically carry the nucleolus organizing region (NOR) in their p12 band, with approximately 40 copies on average, for a total of $300-400$ copies per cell ${ }^{5}$.

Size variation among acrocentric short arms may occur for several reasons. There can be amplification or loss of material from each of their bands or subbands, which are referred to as p11.2, p12, and p13 for all acrocentric chromosomes. Meiotic translocations due to unequal crossover were suggested as one possible reason for $p$-arm variations by Malcolm Fergusen-Smith in $1974^{6}$, which was proven in 2006 in one case with de novo der(21)t(Y;21) $(q 12 ; p 13)^{3}$. With the development of molecular cytogenetic technology and the availability of probes for 15p11.2 (D15Z1) and 22p11.2 (D22Z4), derivatives such as $\operatorname{der}(13) t(13 ; 15)(p 11.1$; p11.1), $\operatorname{der}(21) t(15 ; 21)(p 11.1 ; p 11.1)$ and $\operatorname{der}(21) t(21 ; 22)(p 11.1 ;$ p11.1) have been reported ${ }^{2}$.

In a subset of the $2.38 \%$ individuals in the abovementioned population with short arm enlargement of an acrocentric chromosome, this situation is due to $\operatorname{der}($ acro $) t(Y ; a c r o)(q 12 ; p 1$ ? 2). As reported in $1979^{7}$, chromosome 15 is the most frequently involved chromosome (52\%), followed by chromosomes 22 (33\%), $21(7 \%), 13(4 \%)$, and 14 (4\%). We suggest that most, if not all, of these acrocentric derivatives represent only one side of the coin, i.e., balanced rearrangements originating in single ancestors that might have segregated independently in two unbalanced forms with no major adverse effects on their carriers and spread through the human population. It was suggested in 1993 that the closest homology of $15 p$ and $22 p$ is shared with $Y q 12$, which could explain why $X Y$ bivalents are frequently seen in close proximity to NORs during prophase of male meiosis ${ }^{8}$. Derivatives $\operatorname{der}(\mathrm{Y}) \mathrm{t}(\mathrm{Y} ; \mathrm{acro})(\mathrm{q} 12 ; \mathrm{p} 1 ? 2)$ are repeatedly seen in human cytogenetic findings; some carriers are found by chance in prenatal or parental studies, and others are found among infertile males or children with congenital abnormalities. Similar observations were reported for $\mathrm{CHMs}$ of the pericentric region of chromosome $9^{4}$. However, no study has determined the frequency at which individual acrocentric chromosomes are involved in this chromosomal rearrangement. Only two exploratory orks are available, which found $\operatorname{der}(\mathrm{Y}) \mathrm{t}(\mathrm{Y} ; 15)(\mathrm{q} 12 ; \mathrm{p} 11.2)$ to be involved in $5 / 8$ cases $^{4,9}$.

\footnotetext{
${ }^{1}$ Institute of Human Genetics, University Medical Center Hamburg, Hamburg, Germany. ${ }^{2}$ Jena University Hospital, Friedrich Schiller University, Institute of Human Genetics, Jena,
} Germany. ${ }^{\circledR}$ email: Thomas.Liehr@med.uni-jena.de

Received: 26 March 2021 Revised: 31 May 2021 Accepted: 29 June 2021

Published online: 28 July 2021 
Table 1. Studied cases, few clinical details and result are summarized here.

\begin{tabular}{|c|c|c|c|c|}
\hline case & gender & age & diagnoses & result \\
\hline 1 & Male & 31 years & Infertile & $46, X, \operatorname{der}(Y) t(Y ; 15)(q 12 ; p 11.2)$ \\
\hline 2 & Male & prenatal & Advanced maternal age & $46, X, \operatorname{der}(Y) t(Y ; 15)(q 12 ; p 11.2)$ \\
\hline 3 & Male & 37 years & Infertile & $46, X, \operatorname{der}(Y) t(Y ; 15)(q 12 ; p 11.2)$ \\
\hline 4 & Male & 36 years & Infertile & $46, X, \operatorname{der}(Y) t(Y ; 15)(q 12 ; p 11.2)$ \\
\hline 5 & Male & 3 days & Hexadactyly polycystic kidneys ${ }^{a}$ & $46, X, \operatorname{der}(Y) t(Y ; 15)(q 12 ; p 11.2) p a t$ \\
\hline 6 & Male & 10 years & Mental retardation, autism; father not available for studies & $46, X, \operatorname{der}(Y) t(Y ; 15)(q 12 ; p 11.2)$ \\
\hline
\end{tabular}

anderlying genetic cause detected by exome sequencing.

As chromosomes 15 and 22 are the most frequently identified acrocentrics related to $\operatorname{der}(\mathrm{acro}) \mathrm{t}(\mathrm{Y} ; \mathrm{acro})(\mathrm{q} 12 ; \mathrm{p} 1$ ?2) and probes are available for $15 \mathrm{p} 11.2$ and 22p11.2, we performed the first systematic study of carriers of $\operatorname{der}(\mathrm{Y}) \mathrm{t}(\mathrm{Y} ; \mathrm{acro})(\mathrm{q} 12 ; \mathrm{p} 1 ? 2)$.

\section{MATERIAL AND METHODS}

Chromosome spreads were produced according to standard procedures from PHA-stimulated cultured lymphocytes or the amnion cells of seven male individuals with different clinical indications (Table 1); one male with a normal Y-chromosome was included as a control ${ }^{10}$. Karyotyping was performed based on GTG-banding ${ }^{10}$. Fluorescence in situ hybridization (FISH) was performed as previously reported ${ }^{10}$ using the following probes: commercially available Yq12 (DYZ1) probe, $15 p 11.2$ (D15Z1) probe, subtelomeric Xq/Yqter probe (Abbott/Vysis, Wiesbaden, Germany), 22p11.2 (D22Z4) probe ${ }^{11}$, and a probe for all acrocentric short arms (midi54 microdissection-derived ${ }^{12}$ and/ or acrop-arm probe (Cytocell, Oxford Gene Technology, Cambridge, UK) (cases 5 and 6)).

\section{RESULTS}

In all seven cases, karyotyping revealed a derivative $Y$ chromosome with an aberrant tip of the q-arm, appearing as satellites in most cases. All cases were further studied by FISH analysis with a probe for all acrocentric short arms (midi54 or acro$\mathrm{p}$-arm) and the subtelomeric probe for Yqter. On every $\operatorname{der}(\mathrm{Y})$ analyzed with a probe for all acrocentric short arms, a faint to strong signal was seen. However, no signal could be detected with the subtelomeric probe for Yqter (Fig. 1A). Subsequently, hybridization was carried out with the probes for Yq12, 15p11.2, and $22 \mathrm{p} 11.2\left(\right.$ Fig. $\left.1 \mathrm{~B}_{1}\right)$. In six of the seven cases, the additional material on the long arm of the Y-chromosome showed signals of the D15Z1 probe. The signals were strong in 4/6 cases and weak in $2 / 6$ cases. The seventh case showed no signal for either D15Z1 or D22Z1 (Fig. 1B2).

\section{DISCUSSION}

Both the der(acro)t(Y;acro)(q12;p1?2) and $\operatorname{der}(\mathrm{Y}) \mathrm{t}(\mathrm{Y} ; \mathrm{acro})(\mathrm{q} 12 ; \mathrm{p} 1$ ?2) $\mathrm{CHMs}$ have been reported in the literature. It was demonstrated only for the acrocentric derivatives that chromosomes 15 and 22 were involved in $52 \%$ and $33 \%$ of cases, respectively ${ }^{7}$, while there are limited corresponding data for the reciprocal $\operatorname{der}(\mathrm{Y})^{4,9}$. This is surprising, as (i) D15Z1 and D22Z4 probes have been available for FISH studies for decades, and (ii) in North America, a founder effect has been traced based on a large family with $\operatorname{der}(\mathrm{Y}) \mathrm{t}(\mathrm{Y} ; \mathrm{acro})$ $(\mathrm{q} 12 ; \mathrm{p} 1 ? 2)^{13}$.

The results of the present study together with those of Wilkinson and Crolla ${ }^{4}$ and Kühl et al. ${ }^{9}$ support the hypothesis that $\operatorname{der}(\mathrm{Y}) \mathrm{t}(\mathrm{Y} ; \mathrm{acro})(\mathrm{q} 12 ; \mathrm{p} 1$ ? 2) and $\operatorname{der}(\mathrm{acro}) \mathrm{t}(\mathrm{Y} ; \mathrm{acro})(\mathrm{q} 12 ; \mathrm{p} 1$ ? 2) are reciprocal products of the same kind of rare event in the human population. Chromosome 15 (more precisely, D15Z1) is also the sequence most frequently involved in $\operatorname{der}(\mathrm{Y}) \mathrm{t}(\mathrm{Y} ; \mathrm{acro})(\mathrm{q} 12 ; \mathrm{p} 1$ ?2), as it is found in der(acro)t(Y;acro)(q12;p1?2) ${ }^{7}$. It is important to note that it could be proven only that D15Z1 is most often involved in $\operatorname{der}(\mathrm{Y}) \mathrm{t}(\mathrm{Y} ; \mathrm{acro})$, as the possibility that some of the D15Z1-positive short arms could be derived from chromosome $14(\sim 12 \%$ of the population), 13, 21 or 22 (0.5-4\% of the population) must also be considered ${ }^{1}$. However, based on the available data for der(13)t $(\mathrm{Y} ; 13), \operatorname{der}(14) \mathrm{t}(\mathrm{Y} ; 14), \operatorname{der}(21) \mathrm{t}(\mathrm{Y} ; 21)$ and $\operatorname{der}(22) \mathrm{t}(\mathrm{Y} ; 22)^{7}$, this seems unlikely. Therefore, we recommend that in the case of proven $\mathrm{D} 15 \mathrm{Z1}$ involvement, the notation $\operatorname{der}(\mathrm{Y}) \mathrm{t}(\mathrm{Y} ; 15)(\mathrm{q} 12 ; \mathrm{p} 11.2)$ should be used.

Furthermore, these molecular cytogenetic data enabled us to distinguish at least two similar events in the human population: $t$ $(Y ; 15)(q 12 ; p 11.2$-distal) and $t(Y ; 15)(q 12 ; p 11.2$-proximal), leading to $\operatorname{der}(\mathrm{Y})$ with a less or more intense $\mathrm{D} 15 \mathrm{Z1}$ signal, respectively. According to the literature ${ }^{14}$, it is still challenging for second- and third-generation sequencing approaches to access repetitive DNA stretches of several megabase pairs in length; thus, the determination of the ancestral founder origin and/or recurrent translocation by unequal meiotic crossing over for $t(Y ; 15)(q 12$; $\mathrm{p} 11.2)$ may only be possible in specialized $\operatorname{labs}^{15} \cdot \operatorname{der}(\mathrm{Y})(\mathrm{Y} ; 15)$ is not suspected of having any apparent effect on the phenotype of the carrier in any of the examined cases.

In conclusion, we provide the first evidence that the derivatives $\operatorname{der}(\mathrm{Y}) \mathrm{t}(\mathrm{Y} ; \mathrm{acro})(\mathrm{q} 12 ; \mathrm{p} 1$ ?2) and $\operatorname{der}(\mathrm{acro}) \mathrm{t}(\mathrm{Y} ; \mathrm{acro})(\mathrm{q} 12 ; \mathrm{p} 1$ ?2) observed in the general population are indeed two sides of the same coin due to the translocation $t(Y ; 15)(q 12 ; p 11.2)$. In our small study group of 7 patients, we demonstrated that this event occurred at least twice.

\section{DISCLOSURE}

The authors did not receive any support for this work.

\section{REFERENCES}

1. Liehr, T. Benign \& Pathological Chromosomal Imbalances, Microscopic and Submicroscopic Copy Number Variations (CNVs) in Genetics and Counseling (Academic Press, 2014).

2. Liehr T. Cases with heteromorphisms (2021) http://cs-tl.de/DB/CA/HCM/0-Start. html. Accessed 25 March 2021.

3. $\mathrm{Ng}$, L. K. et al. Prenatal detection of a de novo Yqh-acrocentric translocation. Clin. Biochem. 39, 219-223 (2006).

4. Kosyakova, N. et al. Heteromorphic variants of chromosome 9. Mol. Cytogenet. 6, 14 (2013).

5. Wellauer, P. K. \& Dawid, I. B. Isolation and sequence organization of human ribosomal DNA. J. Mol. Biol. 128, 289-303 (1979).

6. Ferguson-Smith, M. A. Autosomal polymorphisms. Birth Defects Orig. Artic. Ser. 10, 19-29 (1974).

7. Smith, A., Fraser, I. S. \& Elliot, G. An infantile male with balanced Y;19 translocation: review of Y; autosome translocations. Ann. Genet. 22, 189-194 (1979). 


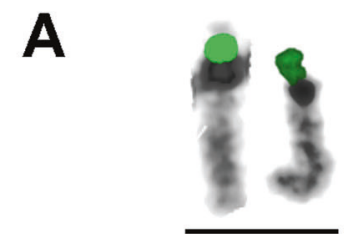

13

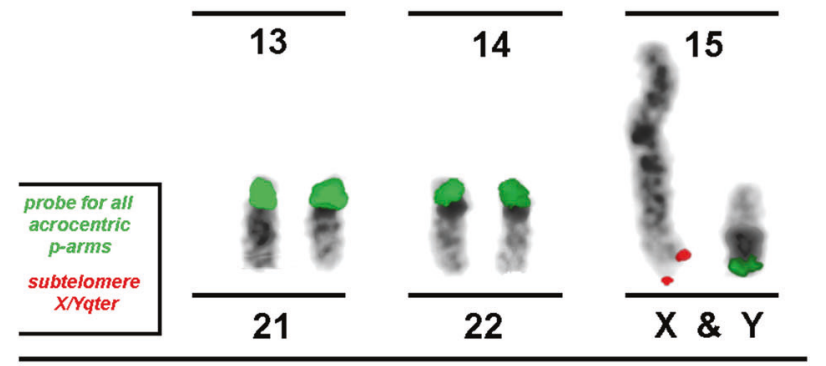

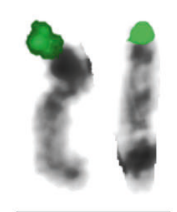

14

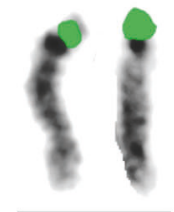

15
$\mathbf{B}_{1}$

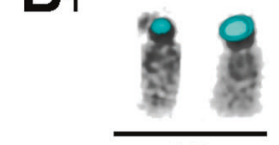

15

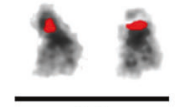

22
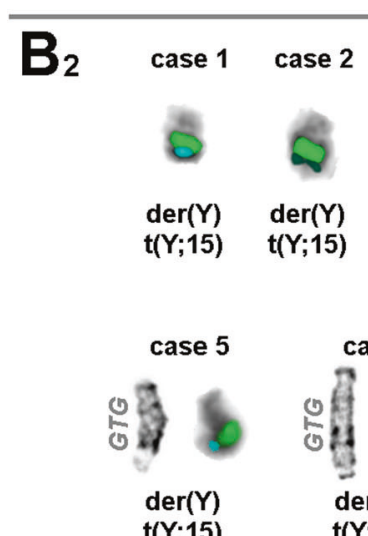

$\operatorname{der}(\mathrm{Y})$ $\mathbf{t}(\mathbf{Y} ; \mathbf{1 5 )}$
$t(Y ; 15)$

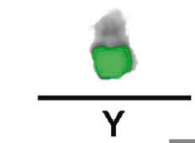

case 4

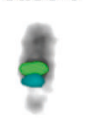

$\operatorname{der}(Y)$ $t(Y ; 15)$
$\operatorname{der}(Y)$

$t(Y ; 15)$

Fig. 1 The results of fluorescence in situ hybridization (FISH) in seven individuals with $\operatorname{der}(\mathrm{Y}) \mathrm{t}(\mathrm{Y} ; \mathrm{acro})(\mathrm{q12} ; \mathrm{p} 1$ ?2) are depicted together with the applied probe sets. The information for the label color for each probe is provided in the legends in parts $A$ and $B$, including the name and location of each probe applied in the corresponding color. A probe for all acrocentric $p$-arms indicated that a part of this region was added in Yqter. A subtelomeric probe for Xqter/Yqter showed a signal only on the X-chromosome, indicating a loss of the tip (PAR2) from the long arm of the Y-chromosome. B1) Partial karyogram of a normal male showing the expected signal pattern for hybridization with probes DYZ1 in Yq12, D15Z1 in 15p11.2, and D22Z4 in 22p11.2. B2) Results of the probe set shown in part B1 of this figure for 7 carriers of $\operatorname{der}(\mathrm{Y}) \mathrm{t}(\mathrm{Y} ; \mathrm{acro})(\mathrm{q} 12 ; \mathrm{p} 1$ ?2); see also Tab. 1. For cases 5 and 6, GTG-banding results are shown beside the FISH results. D15Z1 sequences show high signal intensity in cases 1 , 3,4 , and 6, while in cases 2 and 5, the signal intensities are lower. Case 7 did not show any D15Z1 signal on the $\operatorname{der}(\mathrm{Y})$. None of the 7 cases showed a D22Z4 signal on $\operatorname{der}(\mathrm{Y})$.

8. Wilkinson, T. A. \& Crolla, J. A. Molecular cytogenetic characterization of three familial cases of satellited Y chromosomes. Hum. Genet. 91, 389-391 (1993).

9. Kühl, H., Röttger, S., Heilbronner, H., Enders, H. \& Schempp, W. Loss of the $Y$ chromosomal PAR2-region in four familial cases of satellited $Y$ chromosomes (Yqs). Chromosome Res. 9, 215-222 (2001).

10. Liehr T. (ed.). Fluorescence in situ Hybridization (FISH)—Application Guide 2nd edn. (Springer, 2017).

11. Shiels, C., Coutelle, C. \& Huxley, C. Contiguous arrays of satellites 1, 3, and beta form a 1.5-Mb domain on chromosome 22p. Genomics 44, 35-44 (1997).

12. Mrasek, K. et al. Detailed Hylobates lar karyotype defined by 25-color FISH and multicolor banding. Int. J. Mol. Med. 12, 139-146 (2003).

13. Genest, P. An eleven-generation satellited Y chromosome. Lancet 1, 1073 (1972).

14. Treangen, T. J. \& Salzberg, S. L. Repetitive DNA and next-generation sequencing: computational challenges and solutions. Nat. Rev. Genet. 13, 36-46 (2011).

15. Miga, K. H. et al. Telomere-to-telomere assembly of a complete human X chromosome. Nature 585, 79-84 (2020).

\section{ACKNOWLEDGEMENTS}

The clinical cases were provided by Dr. S. Hentze, Drs. H. and A Fritsche, Dr. Stibbe, Dr. Albrecht and Dr. Ovens-Raeder of Germany. The D22Z4 probe was kindly provided by Prof. Mariano Rocchi of Bari, Italy.

\section{FUNDING}

Open Access funding enabled and organized by Projekt DEAL.

\section{COMPETING INTERESTS}

The authors declare no competing interests.

\section{ADDITIONAL INFORMATION}

Correspondence and requests for materials should be addressed to T.L.

Reprints and permission information is available at http://www.nature.com/ reprints

Publisher's note Springer Nature remains neutral with regard to jurisdictional claims in published maps and institutional affiliations.

\begin{abstract}
(c) Open Access This article is licensed under a Creative Commons Attribution 4.0 International License, which permits use, sharing, adaptation, distribution and reproduction in any medium or format, as long as you give appropriate credit to the original author(s) and the source, provide a link to the Creative Commons license, and indicate if changes were made. The images or other third party material in this article are included in the article's Creative Commons license, unless indicated otherwise in a credit line to the material. If material is not included in the article's Creative Commons license and your intended use is not permitted by statutory regulation or exceeds the permitted use, you will need to obtain permission directly from the copyright holder. To view a copy of this license, visit http://creativecommons. org/licenses/by/4.0/.
\end{abstract}

(c) The Author(s) 2021 